\title{
Prémio Nobel da Química 1986
}

Em Outubro passado, e como já vem sendo hábito desde o princípio deste século, a Academia das Ciências Sueca anunciou o Prémio da Fundação Nobel para a Química. Assim no próximo dia 10 de Dezembro, Dia da festa da Fundação receberão o prémio Nobel, Dudley R. Herschbach, Yan T. Lee e John C. Polanyi. Dudley Herschbach, americano de 54 anos de idade, é professor de Química na Universidade de Harvard, Yuan Lee, de origem chinesa, com 49 anos, depois de pertencer à Universidade de Chicago é actualmente professor de Química na Universidade da Califórnia, Berkeley e John Polanyi canadiano de 57 anos é professor de Física e Química na Universidade de Toronto, Canadá.

Com a atribuição do Prémio Nobel da Química a estes três ilustres químico-fisicos, pode dizer-se, que foi reconhecido o valor da Dinâmica Molecular na interpretação do mecanismo das reacçð̃es químicas. Na realidade antes dos trabalhos iniciados por estes laureados a informação acessivel sobre uma reacção química era obtida através da determinação dos produtos da reacção e da energia consumida ou libertada. Estas observaçðes realizadas em sistemas macroscópicos envolvem grande número de moléculas. Num gás a P.T.N. tem-se $\sim 2.10^{19}$ moléculas $/ \mathrm{cm}^{3}$ e frequências de colisão por molécula da ordem de $5.10^{9} \mathrm{~s}^{1}$. Ora numa reacção, entre a situação inicial e a final podem ocorrer vários passos intermédios sem que, do ponto de vista macroscópico, haja evidência experimental. A reacção química elementar produzida numa colisão entre átomos e/ou moléculas corresponde realmente a uma situação de desiquilíbrio mas devido a posterior transferência de energia em inúmeras colisðes inelásticas não reactivas o sistema evolui para a situação de equilibrio final.

A observação do processo químico elementar foi proposta e realizada experimentalmente, no início dos anos 60, por Dudley R. Herschbach através da dispersão ("scatterring") com feixes moleculares ") cruzados. Nestas experiências as reacçðes podem ser observadas em condiçð̄es de colisão única e com uma resolução temporal da ordem do tempo de colisão, isto é, cerca de $10^{-13} \mathrm{~s}$. Como os desvios dependem das forças envolvidas, as medidas da distribuição angular das partículas dispersas indicam-nos de imediato, pelas suas características, os aspectos delhados da interacção. Por exemplo, é possivel distinguir inequivocamente se uma reacção é directa ou se passa pela formação de um complexo.

As experiências de feixes moleculares constituem pois o meio mais adequado para o estudo da dinâmica da reacção química elementar. No entanto, quando Dudley apresentou as suas propostas de projecto muitos o

1) Esta designação genérica inclui os feixes atómicos e feixes iónicos.

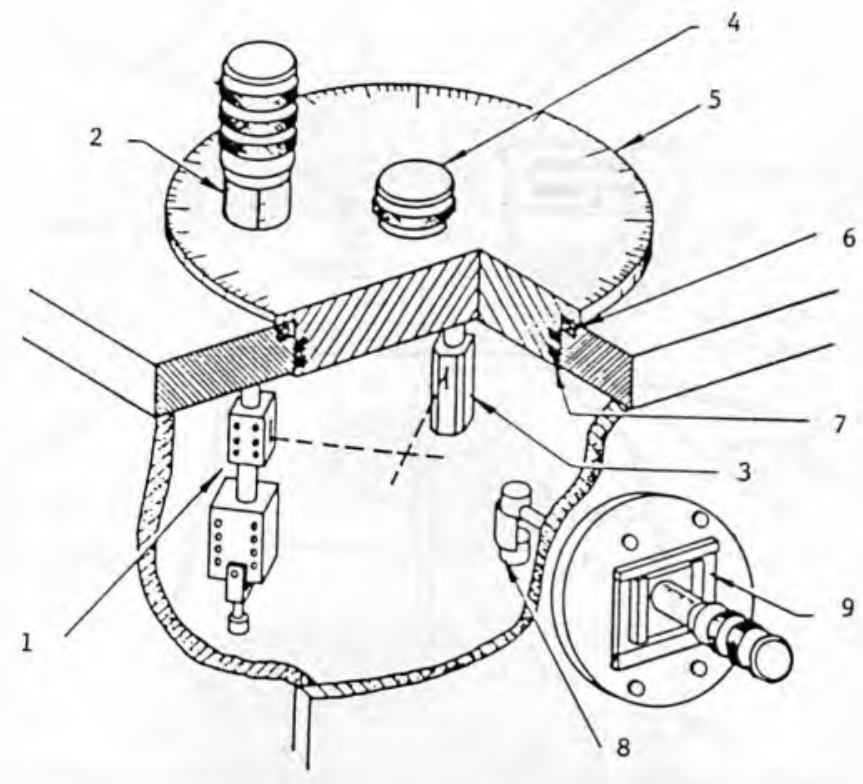

Fig. 1

Peŕspectiva da experiência de feixes moleculares cruzados de D.R. Herschbach. As trapas para bombeamento criogénico, fendas colimadoras, interruptores de feixe e outros detalhes foram omitidos. 1 - Fonte do feixe primário de metais alcalinos com forno de duas câmaras; 2 - Suporte do forno com parafuso micrométrico; 3 - Fonte efusiva para gás do feixe secundário: 4-Suporte da fonte efusiva; 5 - Plataforma móvel; $6-$ Rolamentos de esferas; 7 - Vedação dupla; 8 - Detector por ionização em superfície; 9 - Falange do detector com parafuso micrométrico e falanges deslizantes

consideraram um visionário. Na realidade tratava-se de um projecto fortemente dependente do desenvolvimento e inovação tecnológica. A sua iniciativa, a sua aposta nestas experiências e o reconhecimento das potencialidades do método levaram outros laboratórios à construção de aparelhos de feixes moleculares e ao estudo detalhado da dispersão reactiva e da dispersão em geral. No nosso País podem-se referir os estudos sobre o mecanismo de transferência de electrão (the harpoon) em colisð̄es átomo-molécula a energias hipertérmicas, que têm sido realizados num dos aceleradores moleculares do Centro de Física Molecular das Universidades de Lisboa, no Complexo I do INIC. Estas experiências revelam detalhadamente a parte inicial do processo químico elementar com uma resolução temporal da ordem dos $10^{-14} \mathrm{~s}$.

Nas décadas de 60 e 70 as experiências de feixes moleculares delineados para o estudo de processos de colisão elásticos, inelásticos e reactivos, debatiam-se com três problemas essenciais: a intensidade das fontes, o controle da energia do feixe primário e a sensibilidade 
dos detectores. É então que Yuan Lee, antigo colaborador de Herschbach projecta e constroi por volta de 1970, no James Franck Institute da Universidade de Chicago, um aparelho de feixes moleculares cruzados com características universais, Anteriormente, os processos reactivos envolviam sempre um átomo alcalino, As técnicàs de produção destes feixes eram conhecidas e a deteç̧ão dos átomos alcalinos ou dos seus compostos facilitada pela possibilidade de ionização em superfície.

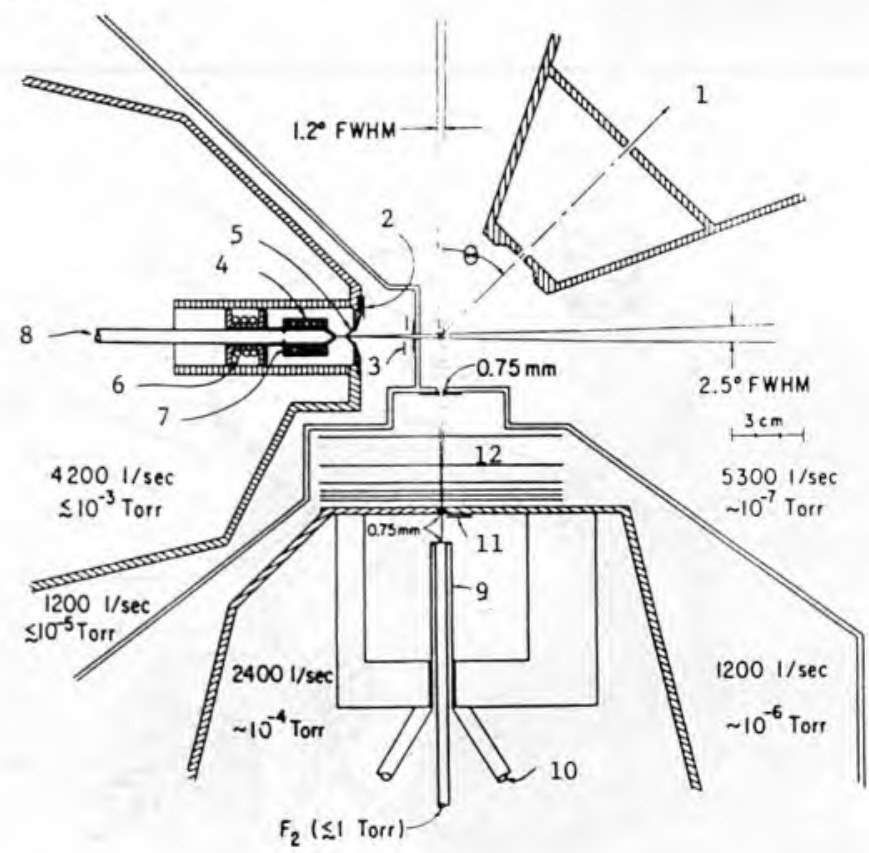

Fig. 2

Desenho esquemático do aparelho de feixes moleculares cruzados de J.T. Lee, na configuração para estudo de reacçס̃es em colisões $\mathrm{F}+\mathrm{C}_{2} \mathrm{H}_{4}$ e outras olefinas. A parte principal do aparelho consiste no espectrómetro de massa que roda no plano dos feixes. I-Espectrómetro de massa tipo quadrupolo: 2 - Bandeira interruptora do feixe; 3-Modulador; 4-Fonte agulheta; 5-Colimador "skimmer"; 6-Circuito de arrefecimento; 7-Aquecedor; 8-Entrada da olefina: 9 - Forno de níquel para dissociação do fluor; 10 -Condutor de grande corrente arrefecido a água; 11 - Bandeira; 12 - Selector de velocidade

No novo aparelho qualquer reacção química elementar poderia, em princípio, ser estudada. No projecto foram optimizados os vários parâmetros e aplicadas as mais recentes técnicas. $O$ detector universal, utilizando bombardeamento electrónico e espectrometria de massa por quadrupolo, fora incorporado numa câmara de ultra-alto vácuo ( $\mathrm{p}<10^{-8} \mathrm{~Pa}=10^{-10} \mathrm{mbar}$ ) o que reduziu consideravelmente o ruído. As fontes utilizadas eram do tipo agulheta ("nozzles") com bombeamento diferencial. Recorde-se que as intensidades dos feixes moleculares diminuem com o inverso do quadrado da distância.

Através de medidas de seç̧ð̃es eficazes diferenciais de reacção e da análise da velocidade dos produtos, Lee e os seus colaboradores, passaram a estudar a reactividade de inúmeros sistemas de átomos e moléculas não envolvendo elementos alcalinos.

Também com este aparelho e através do estudo das secçðes eficazes elásticas em colisðes entre gases raros foram estudados, detalhadamente, os respectivos po-

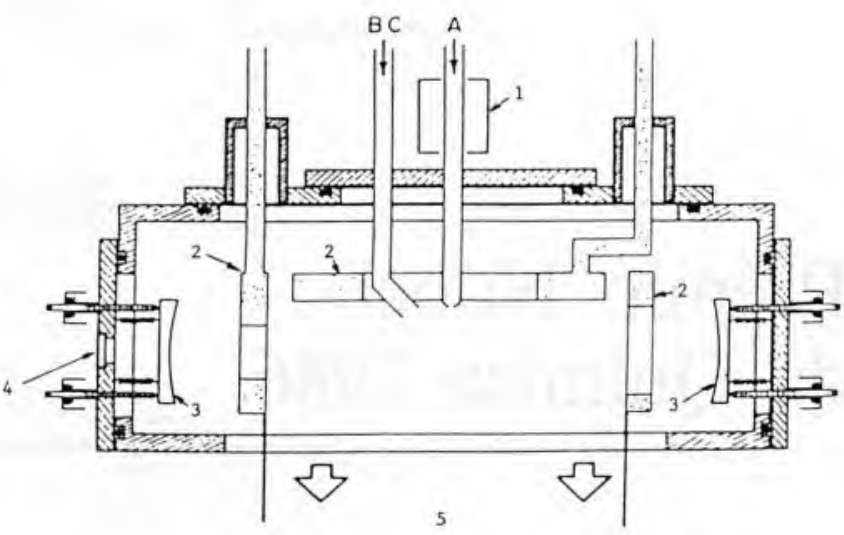

Fig. 3

Desenho esquemático de uma câmara de reaç̧ão utilizada por J. Polanyi. A zona de reacção localiza-se por baixo das entradas de aguIheta dos reagentes $A$ e $B C$. 1 -Descarga de micro-ondas para for-

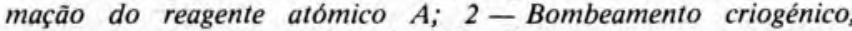
3 - Espelhos reflectores com depósitos de ouro; 4-Janela de safira para o espectrofotómetro; $5-$ Bombas de difusão $500 \mathrm{ls}^{-1}$

tenciais intermoleculares. As moléculas diatómicas homonucleares de gases raros revelam-se idênticas em termos de potenciais intermoleculares reduzidos, justificando deste modo o sucesso da lei de estados correspondentes aplicada a sistemas macroscópicos.

Entretanto Polanyi, no Canadá, segue uma aproximação diferente para o estudo das reacçðes químicas. Mantendo as condiçð̄es de colisðes individuais, portanto a baixas pressðes $\left(\mathrm{p}<10^{-3} \mathrm{~Pa}=10^{-5} \mathrm{mbar}\right)$ e evitando a relaxação por colisão, procura estudar a emissão de radiação dos produtos da reacção (quimiluminescência). Num sistema de fluxos rápidos os reagentes são introduzidos na zona de reacção em condiçð̃es estacionárias. As moléculas produto formadas em estados vibracionais excitados perdem o excesso de energia por radiação na zona do infravermelho. Esta é focada na fenda de um espectrómetro convencional depois de ser colectada por dois espelhos através de reflexð̄es múltiplas. A observação destes espectros de intensidades extremamente baixas, permite determinar as populaçס̃es relativas dos vários estados e as suas constantes de formação.

Atendendo à conservação da energia, no estado final as energias de translação $\mathrm{E}_{\mathrm{T}}$, de vibração $\mathrm{E}_{\mathrm{V}}$ e rotacional $E_{R}^{\prime}$ estão relacionadas entre si através da energia total $E=E_{T}^{\prime} E_{V}^{\prime}+E_{R}^{\prime}$. Daí a extensiva utilização por Polanyi e seus colaboradores de sistemas de coordenadas triangulares para representação da distribuição de energias dos produtos. A sua observação mostra, que em reacçðes átomo-molécula (por ex. $\mathrm{Cl}+\mathrm{HI} \rightarrow \mathrm{I}+\mathrm{HCl}$ ) ocorre frequentemente um acréscimo de energia vibracional conduzindo a uma inversão de população. Estas observaçðes foram essenciais para o desenvolvimento e compreensão dos lasers químicos.

\section{A.M.C. Moutinho}

Centro de Física Molecular das Universidades de Lisboa Departamento de Física, Faculdade de Ciências e Tecnologia (U.N.L.) 